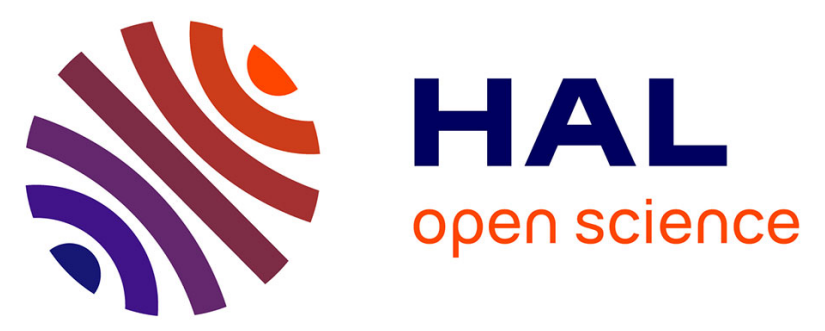

\title{
Designing a Collaborative Personal Assistance Model for Persons with Disabilities: The Portuguese Independent Living Case
}

Patricia Macedo, Filipa Ferrada, Ana Inês Oliveira, Rui Neves Madeira

\section{- To cite this version:}

Patricia Macedo, Filipa Ferrada, Ana Inês Oliveira, Rui Neves Madeira. Designing a Collaborative Personal Assistance Model for Persons with Disabilities: The Portuguese Independent Living Case. 22nd Working Conference on Virtual Enterprises (PRO-VE 2021), Nov 2021, Saint-Etienne, France. pp.652-661, 10.1007/978-3-030-85969-5_61 . emse-03349591

\section{HAL Id: emse-03349591 \\ https://hal-emse.ccsd.cnrs.fr/emse-03349591}

Submitted on 25 Nov 2021

HAL is a multi-disciplinary open access archive for the deposit and dissemination of scientific research documents, whether they are published or not. The documents may come from teaching and research institutions in France or abroad, or from public or private research centers.
L'archive ouverte pluridisciplinaire $\mathbf{H A L}$, est destinée au dépôt et à la diffusion de documents scientifiques de niveau recherche, publiés ou non, émanant des établissements d'enseignement et de recherche français ou étrangers, des laboratoires publics ou privés. 


\title{
Designing a Collaborative Personal Assistance Model for Persons with Disabilities: The Portuguese Independent Living Case
}

\author{
Patrícia Macedo $^{1,2}$, Filipa Ferrada ${ }^{1,2,3}$, Ana Inês Oliveira ${ }^{1,3}$, Rui Neves Madeira ${ }^{2,4}$ \\ ${ }^{1}$ Uninova Institute, Centre of Technology and Systems (CTS), Portugal \\ \{faf, aio\}@uninova.pt \\ ${ }^{2}$ Sustain.RD center, ESTSetúbal, Instituto Politécnico de Setúbal, Campus do IPS, Setúbal, \\ \{patricia.macedo,rui.madeira\}@estsetubal.ips.pt \\ ${ }^{3}$ Faculty of Sciences and Technology, NOVA University of Lisbon, Caparica, Portugal \\ ${ }^{4}$ NOVA LINCS, FCT, NOVA University of Lisbon, Caparica, Portugal
}

\begin{abstract}
This paper presents an ongoing research work that aims to develop governance models and ICTs to enable and empower persons with disabilities according to the orientations settled in the Convention on the Rights of Persons with Disabilities. Starting from the study of the current model of Independent Living Support adopted in Portugal and its practical limitations, we propose a model based on the collaborative networks scientific discipline. This new model aims to guarantee an environment in which all the involved participants can improve and combine their contributions toward providing Personal Assistance to persons with disabilities. The paper also presents a Web platform (SEU - Services to Empower yoU) designed to support offline services acquisition, providing a user interaction adapted to different types of disabilities. Furthermore, we propose an update to the platform SEU to be compliant with the proposed collaborative model.
\end{abstract}

Keywords: Persons with disabilities, independent living, personal assistant, collaborative networks, offline services, digital accessibility.

\section{Introduction}

With the 2030 Agenda for Sustainable Development adoption, Member States pledged to leave no one behind, including Persons with Disabilities (PwD). This political commitment is in line with the United Nations Convention on the Rights of Persons with Disabilities (CRPD) that was ratified by 177 states in March 2019. Moreover, CRPD recognizes the critical role of information and communication technologies (ICTs) in enabling and empowering PwD and ensuring that they fully enjoy human rights and fundamental freedoms [1]. However, ICTs are not the only critical enablers, as several initiatives worldwide have shown that collaborative projects had a positive impact on supporting PwD [2]. 
The CRPD considers that one of the pillars of the Independent Living Movement is providing personal assistance (PA) based on individual needs assessment and the life situation of each individual. Most European countries have developed policies and specific legislation to guarantee access to PA for persons with disabilities [3]. In Portugal, just in 2017, the government launched the Independent Life Support Model (MAVI) for people with severe physical or mental limitations, providing funds for pilot projects. The model is based on three dimensions agents: (i) PwD who benefits from PA; (ii) PwD; and (iii) Support Center for Independent Living (CAVI). The Support Center is the entity that is responsible for selecting candidates and giving them the necessary and possible support according to the available funding and the existing conditions [4]. There are not yet available studies and data about the effectiveness of this organization model; however, there are two important issues that have been informally raised from interviews with some agents involved. First, how to provide ICT solutions adapted to these persons' specific characteristics, which would facilitate the process of managing the personal assistance needed? Second, how collaborative models can be integrated to provide personalized services?

This paper presents an undergoing exploratory research work where a new model, based on collaborative networks, is proposed as a promising approach for supporting collaboration among all the involved entities that provide Independent Living for PwD. This exploratory research work is part of the funded project called Services to Empower yoU (SEU) - Exploring Interfaces for people with disabilities [5], where a Web Platform for offline services acquisition with accessible interfaces was designed and developed using Participatory Design. During the participatory design process, some partners identified the difficulties they had in efficiently managing the allocation of personal assistants. Therefore, it raised a question regarding how the platform SEU could be adapted to address the identified issue as it provides accessible interfaces for different types of PwD.

The research work presented in this paper adopted the design science research methodology [6], in which a set of artifacts (models) supports more efficiently Independent Living of PwD. These artifacts were developed grounded in the corpus of knowledge of Collaborative Networks $(\mathrm{CN})$ [7]. The paper presents how they can be used in practice, adapting the platform SEU to instantiate them in order to validate the practical relevance of the proposed models.

\section{Background and Related Work}

The right to live independently and be included in the community is set out in Article 19 of the CRPD. In this line, countries worldwide have been preconizing different actions to give effective support to PwD, combining various environmental and individual factors that allow PwD to control their own lives [1]. In Europe, policy actions like the Strategy for the Rights of Persons with Disabilities 2021-2030 [8] are devoted to achieving further progress in ensuring the full participation of persons with disabilities by building new guiding actions based on past achievements. Social and community movements like ENIL [9] or Independent Living [10] have also played an impressive role by promoting self-determination, equal opportunities, and self-respect for PwD.

The inclusion of Personal Assistance (PA) in PwD is essential to support living and inclusion in the community and prevent isolation. The concept was proposed by Ratzka [11] 
in Sweden and is now present in many countries worldwide. PA can be defined as the necessary assistance required by a disabled person to ensure that $\mathrm{s} / \mathrm{he}$ can participate as a full and equal member of society [12]. The individual manages this assistance to guarantee the right choice and control, presupposing adequate support, and it can be adapted to different circumstances both within and outside the home. It can include support with personal care, help with household tasks and administration duties, facilitating attendance at work or college, as well as enabling social activities and participation in community life. Nevertheless, and despite the efforts, PA is still not widely available, and a large number of persons with a disability are still segregated in institutions [13].

In Portugal, via a governmental law ${ }^{1}$ in 2017, the MAVI program has been established, allowing PA to PwD to perform a set of activities that they cannot accomplish alone. The implementation of the MAVI is done through the Centers for Supporting Independent Life (CAVI) since they are the structures responsible for providing personal assistance to PwD. CAVIs are created as autonomous units of Non-Governmental Organisations for PwD. Their mission is to assume management, coordination, and support functions of the PA services within the scope of independent living. Each CAVI is responsible for managing the requests of PwD for PA service and recruiting assistants to satisfy the demands. Any citizen can apply to be a PA in a CAVI. There is a personal assistants database with the contacts and availability information of people who have signed up to work as a PA.

There are several types of services that can be requested, and there are also some services that can require more than one PA at the same time (e.g., a person with overweight may need two people at the same time to help with the bathing). A PA service can be characterized in two dimensions: categorization of service (e.g., personal care, travel support, education, etc.) and time (duration, time of the day, days of the week, etc.). However, the PwD is who decides how many PAs s/he needs and selects them. An individual document is drawn up in which the hours, activities and other specific details relating to PA are recorded.

It is easy to understand that for a PwD to fully benefit from PA services is needed an organizational structure that supports collaboration and coordination between operational assistants. Currently, many networks worldwide work in the disability field, supporting and promoting independent living and empowering full participation of PwD in society via PA (e.g., ENIL, ILMI, IEDisabilities, NDIS, among others). However, most of them lack grounded models for collaboration between PwD and PA regarding the organization, governance, and service planning and management. The $\mathrm{CN}$ model presented in this paper proposes a potential solution to solve these problems.

Regarding Web platforms explicitly designed to facilitate the acquisition of offline services for PwD, only a few initiatives are known. A pioneering project developed in Taiwan, where a platform called Eden was developed, aimed to provide point-to-point transit services by connecting elderly and disabled passengers to drivers [14]. However, there is no reference that the mobile app developed for the passengers has adapted user interfaces to support specific needs. A case study conducted in Australia [15] of a Web-based platform, which works similarly to Trip Advisor by providing a means through which disability service users can share information about their experiences that can inform subsequent choices, has shown the importance of this kind of solutions to empower PwD. The adaptation of the Web platform

\footnotetext{
${ }^{1}$ https://dre.pt/web/en/home/-/contents/108265124/details/normal
} 
SEU to support the $\mathrm{CN}$ model, as proposed in this work, envisages allowing better PA services, providing, at the same time, accessible interfaces for different types of PwD.

\section{Collaborative Personal Assistance Model for Persons with Disabilities}

The service being provided by a Personal Assistance Network results from the specific requirements of each individual (PwD) and, therefore, completely customized and personalized to her/ his needs. Given the potential specificity of each service, it might often be necessary to create a new service based on the composition of services $[16,17]$ provided by several PAs, building a team that will typically dissolve after the service is provided. Nevertheless, depending on the nature of the service, this duration may vary.

Hence, collaboration among PA and PwD introduces some aspects that should be considered in terms of organization, governance and service planning and management. Therefore, it is crucial to understand the nature of these networks and how they can be modeled. In this line, and considering the core context, the collaborative personal assistance (CoPA) model integrates three kinds of networks: independent living model network, independent living support network, and PA network. As such, Erreur ! Source du renvoi introuvable. illustrates the different networks involved in the provision of services to PwD, focusing on their interactions.

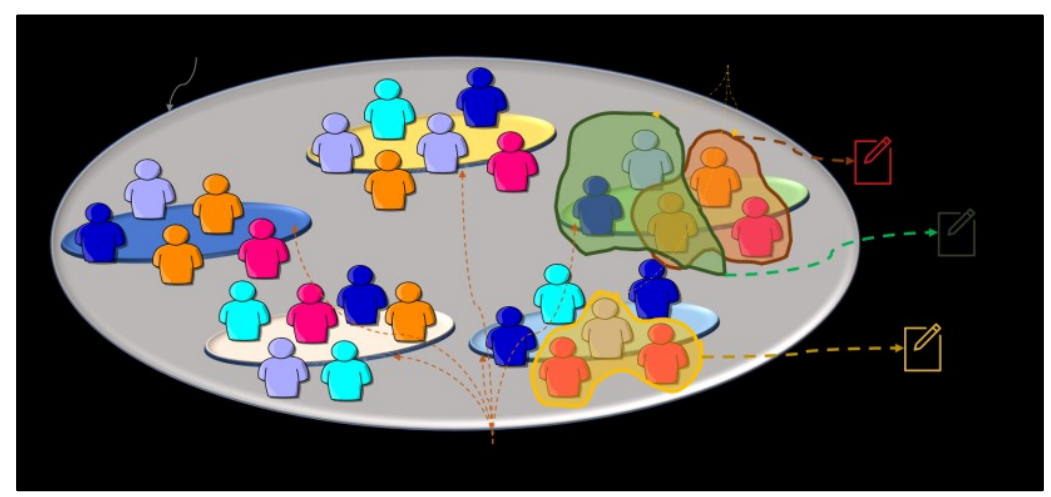

Fig. 1. Different networks involved in the provision of services to PwD.

Being the provision of services a collaborative process to support all the involved stakeholders, a CN can be instantiated by combining the different characteristics that these networks have, such as network typology, duration, membership, members from different networks, etc. Thus, it is aimed to model an environment that nurtures collaboration amongst all entities that are involved in services provision to PwD. In this direction, the scientific discipline of collaborative networks $[7,18]$ introduces some concepts and models that cope with the demanding requirements for such environment, namely virtual organizations breeding environments (VBEs), professional virtual communities (PVCs), virtual organizations (VOs), and virtual teams (VTs) [19]. On the one hand, the VBEs and PVCs increase the level of preparedness of organizations and individuals in succeeding in collaboration; on the other hand, VOs and VTs are temporary consortiums of organizations 
or individuals, supported by computer networks, which join their competencies to strategically and adequately accomplish a common goal [19]. Considering these concepts, Erreur ! Référence non valide pour un signet. includes a description of the proposed networks for the CoPA model.

Table 1. Description of involved collaborative networks in the CoPA model.

\begin{tabular}{ll}
\hline Network & Description \\
\hline $\begin{array}{l}\text { Independent Living } \\
\text { Model Network }\end{array}$ & $\begin{array}{l}\text { Long-term alliance, with the main characteristics of a VBE, that involves the } \\
\text { governing, regulation and certification of different types of entities that are } \\
\text { willing to provide independent living support, namely the Independent } \\
\text { Living Support Networks. }\end{array}$ \\
\hline $\begin{array}{l}\text { Independent Living } \\
\text { Support Network }\end{array}$ & $\begin{array}{l}\text { Long-term alliance, with the characteristics of a PVC, that involves distinct } \\
\text { supporting PAs, with different competences, in a defined region, that are } \\
\text { willing to collaborate in order to provide a customized and personalized } \\
\text { independent living service to PwD. }\end{array}$ \\
\hline Personal Assistance & $\begin{array}{l}\text { Temporary consortium, with the characteristics of a VT, involved in the } \\
\text { provision of customized and personalized services to PwD. }\end{array}$ \\
\hline
\end{tabular}

The ARCON modeling framework [18] is perceived as the most relevant in the CN domain once it defines a comprehensive set of concepts and entities covering both endogenous elements and exogenous interactions perspectives of CNs. Similarly to other works describing CNs, the ARCON framework was used to systematically and comprehensibly describe the different aspects of the proposed $\mathrm{CNs}$ in the CoPA model. In this case, despite all the specificities, for a general representation of concepts and related relationships, it was only used the ARCON's Model Intent general representation layer, combined with the main elements of the endogenous description. The following characterization (see Table 2 and Table 3) focuses on the independent living support network and personal assistance network, considering the operation phase of the lifecycle of the networks. In contrast, the Independent Living Model Network will be characterized in further works since its characteristics will emphasise the governing and certification for independent living support networks.

\section{Adaptation of SEU to Support the CoPA Model}

The platform SEU (Services to Empower You) [5], as explained before, was developed in the scope of a larger project and intended to respond to the needs raised by PwD when they wish to acquire services through the Web. Services platforms are usually grouped into three categories [20], according to what they facilitate: (i) transportation; (ii) offline services; (iii) online services. The SEU platform falls into the second category as it is geared to support services that are local and rely on the physical presence of the service provider. The Web platform SEU integrates the following features (see Fig. 2): (i) various customer and service acquisition models; (ii) validation of customers and service providers; (iii) use of adapted digital resources, allowing the automatic provision of adapted interfaces. The need for the supervisor role stands out, allowing the existence of supervised PwD, where the acquisition of a service will require the authorization of her/his supervisor to protect users with cognitive 
impairment. Sometimes, or due to the characteristics of the PwD, there is a need for a third person to acquire the service; hence, the introduction of the third type of client, the caregiver.

Table 2. Characterization of Independent Living Support Network.

\begin{tabular}{ll}
\hline Independent Living Support Network \\
Endogenous Elements \\
\hline Subspace: Structural \\
\hline Roles & $\begin{array}{l}\text { Administrator can be performed by a PA responsible for the network governance } \\
\text { (can be assisted by a board of directors). All members are PAs willing to collaborate } \\
\text { to provide customized services to PwDs. The potential customers are PwD that } \\
\text { request a service. }\end{array}$ \\
\hline Relations & $\begin{array}{l}\text { Control Supervision ensured by the administrator. All members are responsible for } \\
\text { cooperation and collaboration, and exchange and sharing of information, and } \\
\text { establishing Trusting mechanisms. }\end{array}$ \\
\hline Network & Long-term alliance that involves the network governance. \\
\hline Subspace: & Componential \\
\hline ICT & $\begin{array}{l}\text { A software platform to support the independent living support network collaboration } \\
\text { and management, allowing the registration of new members, their profiles information }\end{array}$ \\
Resources & $\begin{array}{l}\text { and the requests from potential customers (PwD). This platform can be part of the } \\
\text { platform used by independent living model network. }\end{array}$ \\
\hline Human & $\begin{array}{l}\text { Member of the independent living model network. } \\
\text { Resources }\end{array}$ \\
\hline Knowledge & $\begin{array}{l}\text { Detailed profile of members; information about potential customers; network profile } \\
\text { data; main common ontologies for common understanding; shared resources } \\
\text { Resources }\end{array}$ \\
\hline
\end{tabular}

Table 3. Characterization of Personal Assistance Network.

\section{Personal Assistance Network}

\begin{tabular}{ll} 
Endogenous Elements \\
\hline Subspace: Structural \\
\hline Roles & $\begin{array}{l}\text { Planner is responsible for the creation of a PA network; the Coordinator is responsible } \\
\text { for the coordination of the PA network during its duration; the Partner represents all the } \\
\text { PAs involved in the provision of the service to the PwD. }\end{array}$ \\
\hline Relations & $\begin{array}{l}\text { Control Supervision under the responsibility of the Coordinator; Collaboration, } \\
\text { Exchanging and Sharing between all partners; The constant trust establishment among } \\
\text { partners is essential. }\end{array}$ \\
\hline Network & Virtual team involved in the provision of a composed service to PwD. \\
\hline Subspace: Componential \\
\hline $\begin{array}{ll}\text { ICT } \\
\text { Resources }\end{array}$ & $\begin{array}{l}\text { A software platform to support the creation and management of the personal assistance } \\
\text { network. This platform can be part of the platform used by independent living support } \\
\text { network. }\end{array}$ \\
\hline $\begin{array}{l}\text { Human } \\
\text { Resources }\end{array}$ & $\begin{array}{l}\text { Different partners can be allocated to specific services provided to the PwD. } \\
\text { Knowledge }\end{array}$ \\
$\begin{array}{l}\text { Shared resources; Templates with models or reference documents to be instantiated for } \\
\text { a specific use case; Main common ontologies used to facilitate the common } \\
\text { understanding among the network partners; etc. }\end{array}$ \\
\hline
\end{tabular}


The specified user registration model also foresees that all registrations are subject to approval by the platform manager to ensure that all service providers are validated, and that client information is valid. It is also proposed that the platform manager has the role of introducing the digital components that will allow the information about a service to be available in an accessible way, which can be, for instance, the introduction of a video with the description of a service in LGP (Portuguese Sign Language).

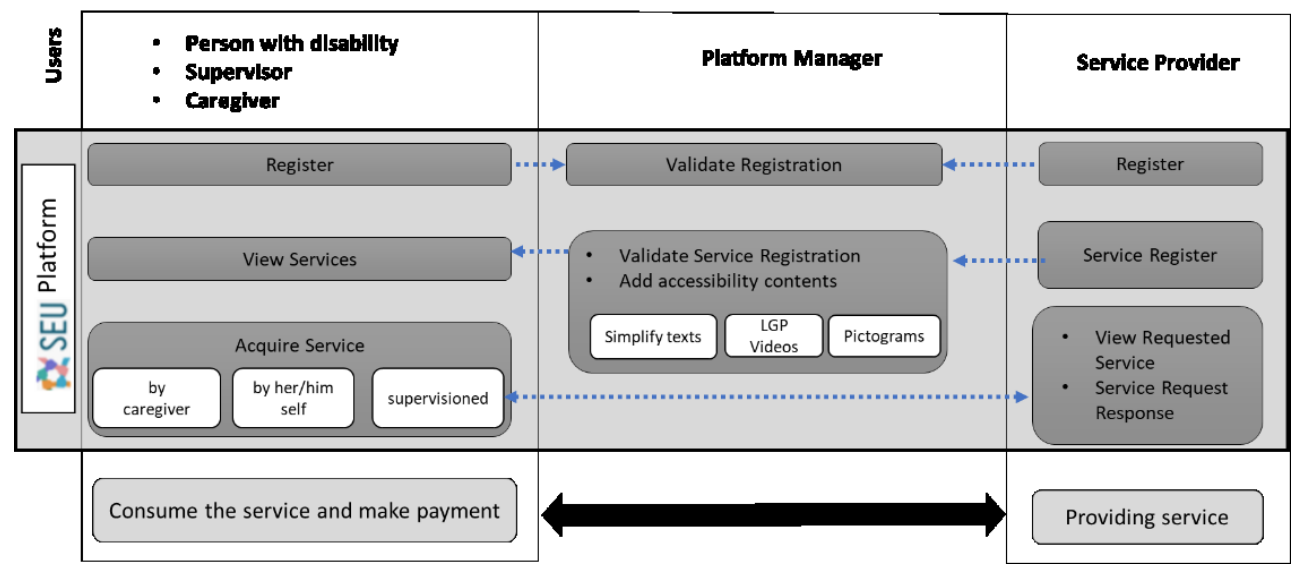

Fig. 2. SEU Platform: Conceptual Model.

The platform has a client-server architecture based on RESTful Web services. MongoDB is used to implement the data repository, Node.JS and the Express.JS framework are the technologies used for the implementation of the server and services logic layer, with Vue.JS being used to support the client layer development. The user interaction is adapted according to the user profile (see Fig. 3A), and each service description has specific information about the types of available adaptations (see Fig. 3B).

Since the platform already has an accessible interface to support users with distinct disabilities (visual, auditory, cognitive, physical), and implements all the components required to support multiple types of clients and services providers, it is presented how it can be adapted to support the CoPA model presented in section 3.

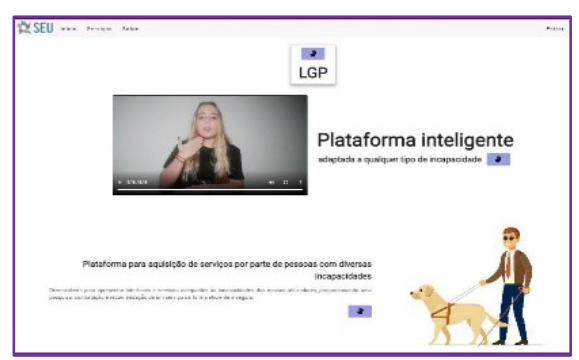

(A) Auditory Adaptation

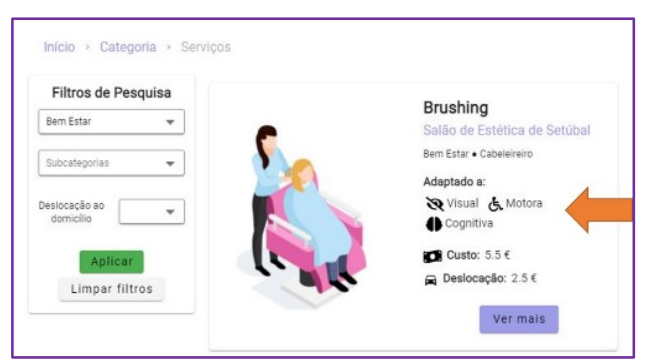

(B) Services View-Target Group is indicated

Fig. 3. Platform SEU: Examples of Accessibility Adaptation and Information Adaptation. 
The SEU's Conceptual Model supports three user groups: Client; Platform Manager; and Service Provider. In the scope of the CoPA model, the role of the service provider is replaced by the role of PA, which is the one that provides the service directly to the PwD. Since PAs integrate Independent Living Networks, and these integrate an Independent Living Network, both user roles must be supported by the platform SEU. Fig. 4 presents the conceptual model Collaborative-SEU (C-SEU), representing the primary users of the platform and the main operations allocated to each one, in the scope of providing integrate plans of personal assistance in the scope of Independent Living Models Networks.

Another important feature that should be designed and implemented is the possibility of service composition. A client should be able to apply for a set of services that the same PA cannot provide. So, the C-SEU should propose a plan of services according to the requirements of the client and the PAs available on the Independent Living Networks to which the client belongs. This coordination of services to build a personalized assistance plan is one of the challenges identified in the C-SEU model for the platform. According to the model proposed, this personalized assistance plan will be executed by a temporary virtual network of personal assistants created with that purpose.

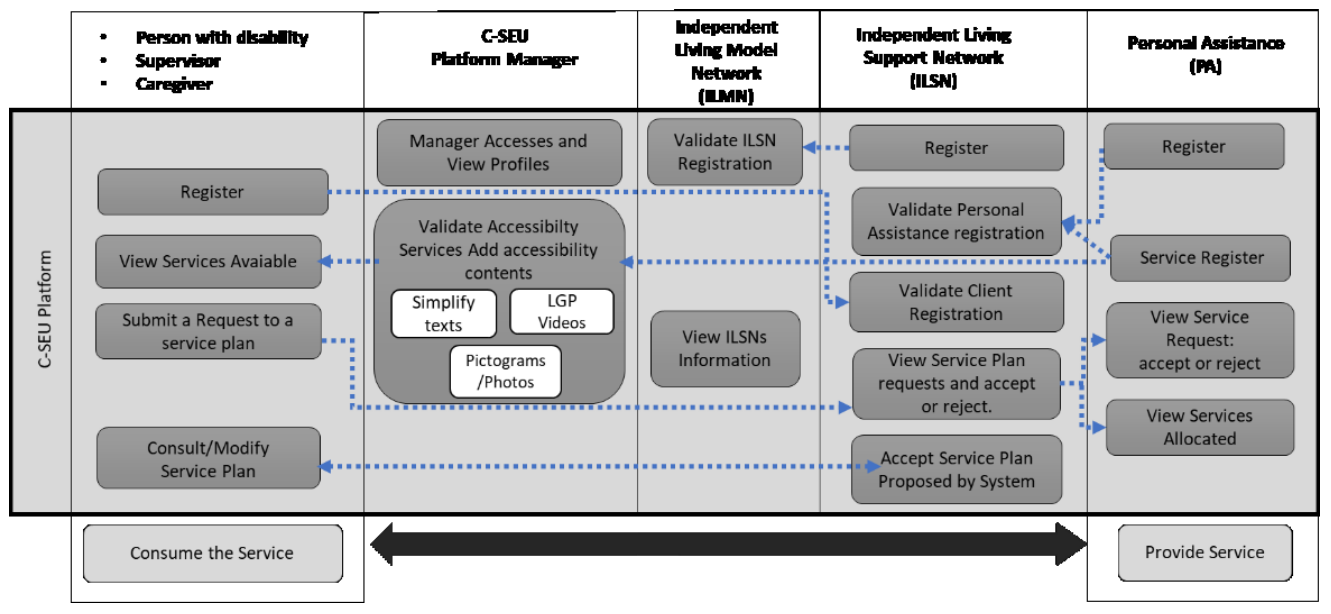

Fig. 4. Conceptual Model C-SEU.

\section{Conclusion and Future Work}

This paper presents ongoing research aiming to develop governance models and ICTs to enable and empower PwD according to the orientations settled in the Convention on the Rights of Persons with Disabilities. Two main contributions were achieved: i) the CoPA model - a governance model supported by a collaborative network paradigm that aims to guarantee an environment in which all the involved participants can improve and combine their contribution for the provision of Personal Assistance to PwD; ii) a conceptual model for a Web platform, based on SEU as the case study, which supports the acquisition of offline services and presents a user interaction adapted to diverse types of disabilities, in order to be compliant with the CoPA model. 
Two main aspects must be carried out concerning the CoPA model. Firsty, each of the three proposed networks must be further characterized within the scope of the ARCON reference model. Secondly, the model that serves to support the Portuguese Personal Assistance governance model known as MAVI needs to be validated next to the institutions that run CAVIs.

According to the research methodology adopted, the validation of the conceptual models proposed comprises the practical relevance of the proposed models. The partners of the research project SEU, Portuguese institutions that work with PwD (APPDA-Setubal, Health School of Alcoitão, and Accessible Portugal), have expertise in Personal Assistance and will be involved in the evaluation of the proposed artifacts, validating our solution against the identified problem.

Acknowledgements. Project funded by the Polytechnic Institute of Setúbal, through the internal Research Support Program and by the Portuguese "Fundação para a Ciência e Tecnologia" "Strategic program UIDB/00066/2020" (UNINOVA-CTS project).

\section{References}

1. United Nations: United Nations Convention on the Rights of Persons with Disabilities, https://www.un.org/disabilities/documents/convention/convention_accessible_pdf.pdf, last accessed 2021/04/28.

2. Lilly Cheng Sandra Levey, L.-R., Lilly Cheng, L.-R.: Collaborative Approaches to the Support of People with Disabilities: The Underserved and Unserved. (2019). https://doi.org/10.1159/000492530.

3. Nally, D., Moore, S.S., Gowran, R.J.: How governments manage personal assistance schemes in response to the United Nations Convention on the Rights of Persons with Disabilities: A Scoping Review. Disabil. Soc. (2021). https://doi.org/10.1080/09687599.2021.1877114.

4. Silva, J.M.: The Portuguese Independent Living Support Model (MAVI). Iris J. Nurs. Care. 2, (2020). https://doi.org/10.33552/ijnc.2020.02.000550.

5. Macedo, P., Miranda, P., Alburqueue Santos, P., Ferrada, F., Paquete, P., Castro, C.: Plataforma de Serviços SEU - Estudo de Interfaces de Utilizador para Pessoas com Deficiência ou Incapacidade. In: VI CONFERÊNCIA INTERNACIONAL PARA A INCLUSÃO. pp. 237247 (2020)

6. Peffers, K., Tuunanen, T., Rothenberger, M.A., Chatterjee, S.: A design science research methodology for information systems research. J. Manag. Inf. Syst. 24, 45-77 (2007). https://doi.org/10.2753/MIS0742-1222240302.

7. Camarinha-Matos, L.M., Afsarmanesh, H.: Collaborative networks: a new scientific discipline. J. Intell. Manuf. 16, 439-452 (2005). https://doi.org/10.1007/s10845-005-1656-3

8. Commission, E.: Strategy for Rights of Persons with Disabilities 2021 - 2030, https://ec.europa.eu/commission/presscorner/api/files/document/print/en/qanda_21_813/QAN DA_21_813_EN.pdf, last accessed 2021/04/20.

9. ENIL - European Network on Independent Living: European Network on Independent Living Personal Assistance Services in Europe 2015-Report, http://www.enil.eu/wpcontent/uploads/2012/06/Personal-Assistance-Service-in-Europe-Report-2015.pdf, (2016).

10. Independent Living Institute (ILI), https://www.independentliving.org/, last accessed 2021/04/23.

11. Westerberg, B.: Personal Assistance: a revolution for people with disabilities. In: 7th 
International Conference on Social Work in Health and Mental Health, Southern California, Los Angeles. , Los Angeles (2013).

12. Center for Independent Living: National Leader Forum Personal Assistance Services Report, https://ilmi.ie/wp-content/uploads/2018/07/Personal-Assistance-Report-2016-.pdf, (2016).

13. Mladenov, T.: What is good personal assistance made of? Results of a European survey. Disabil. Soc. 35, 1-24 (2020). https://doi.org/10.1080/09687599.2019.1621740.

14. Wu, Y.J., Liu, W.J., Yuan, C.H.: A mobile-based barrier-free service transportation platform for people with disabilities. Comput. Human Behav. 107, (2020). https://doi.org/10.1016/j.chb.2018.11.005.

15. McLoughlin, I., McNicoll, Y., Beecher Kelk, A., Cornford, J., Hutchinson, K.: A 'Tripadvisor' for disability? Social enterprise and 'digital disruption' in Australia. Information, Commun. Soc. 22, 521-537 (2019). https://doi.org/10.1080/1369118X.2018.1538382.

16. Camarinha-Matos, L.M., Ferrada, F., Oliveira, A.I., Rosas, J., Monteiro, J.N.: Integrated care services in ambient assisted living. In: 15th IEEE International Conference on e-health Networking, Applications and Services (IEEEHealthcom 2013). , Lisbon (2013). https://doi.org/10.1109/HealthCom.2013.6720666

17. Baldissera, T.A., Camarinha-Matos, L.M.: SCoPE: Service composition and personalization environment. Appl. Sci. 8, (2018). https://doi.org/10.3390/app8112297.

18. Camarinha-Matos, L., Afsarmanesh, H.: Collaborative networks: Reference modeling. Springer Science \& Business Media (2008). https://doi.org/10.1007/978-0-387-79426-6.

19. Camarinha-Matos, L.M., Oliveira, A.I., Demsar, D., Sesana, M., Molina, A., Baldo, F., Jarimo, T.: VO Creation Assistance Services. In: Methods and Tools for Collaborative Networked Organizations. pp. 155-190. Springer, Boston, MA. https://doi.org/10.1007/978-0-38779424-2 6

20. Fabo, B., Beblavý, M., Kilhoffer, Z., Lenaerts, K.: An overview of European platforms: Scope and business models. Publications Office of the European Union, Brussels (2017). 